31), and his invention of the 'bra' (the left half of an expression contained within a bracket); or his referring to transformation theory as "my darling".

And when did Pais first meet Wolfgang Pauli? At a 1946 party in Bohr's home, of course. The whole chapter on Pauli is so engrossing as to become unstoppable, even troubling reading: how could Pauli in 1921 (aged only 21) publish a review of the relativity theory that was so good as to merit Einstein's praise? Easy: he started early, during the boring hours at the Gymnasium, when he surreptitiously read Einstein's papers under his desk. We follow the development of Pauli's thoughts on physics, notably on quantum physics and the relations between spin and quantum statistics. A lifelong interest of his, whichled to that pillar of physics known as the spin-statistics theorem, was, sadly, to be formulated only in 1958, the year of Pauli's death.

Indirectly, yet profoundly, we sometimes get the perspective of Pais himself, going well beyond personal recollections. During the description of Eugene Wigner's life, for example, the author admits to a difficulty in "grasping the personalities" of Hungarianborn physicists such as Leo Szilard, Edward Teller, John von Neumann (officially Margittai Neumann Janos Lajos) and, of course, Wigner himself. There is a quaint, lightly exotic something that sets the Hungarians apart from the more classic Mittel-European variety of the twentieth-century physicists who changed the world for ever.

There is a wider lesson, in history and sociology, to be learnt here, especially for younger readers. Of the 17 biographies in Pais' book, 13 are of European-born (and educated) scientists. Some, such as Isidor Rabi, are from countries like Galicia, which shifted from being a province of the AustroHungarian Empire to becoming part of postSecond World War Poland; some, like Pauli, simply say "I am European".

Pauli had his reasons. He was born and educated in Vienna, studied in Munich, was appointed ETH-Zürich full professor at 28, became, by default, German after the Anschluss (1933), but, in 1938, was denied Swiss citizenship because of his insufficient knowledge of "Schwitzerdeutch" (while, of course, his Hochdeutch was impeccable). Yet, after the war and the Nobel prize, he turned down lucrative appointments in the United States to come back to Zürich and, finally, to become a Swiss citizen. Of the other Pais personae, two are Chinese-born (Tsung Dao Lee and Chen Ning Yang), and only two, Mitchell Feigenbaum and Robert Serber, were born in the United States.

What better way to depict, besides the lives and science of the famed, the twentieth-century wave of migration of European culture towards the United States. This was a phenomenon of staggering proportions and extent. A different, but also very interesting, account of the same global phenomenon is in a lesser-known book by Laura Fermi, Illustrious Immigrants (University of Chicago Press, 1968), which includes physicists, of course, but ranges also to other sciences, and to music and the arts.

In covering a wide range of topics, from relativity to chaos theory, Pais' life-andscience stories provide, above all, the staple on which young (and not so young) scientists should feed their ambitions. Alternatively, we can just enjoy and be enriched, both culturally and emotionally.

Giovanni F. Bignami is at the Agenzia Spaziale Italiana, Viale Liegi 26, 00198 Rome, Italy.

\section{n......................... Wacky star of the Renaissance}

\section{Cardano's Cosmos: The Worlds and Works of a Renaissance Astrologer \\ by Anthony Grafton \\ Harvard University Press: 2000. 284 pp.

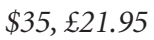

\section{Owen Gingerich}

Girolamo Cardano was seen by his 1950s biographer, Oystein Ore, as "the gambling scholar", the man who introduced ideas of probability to Western civilization. Cardano's Ars Magna, the book containing the general solution of the cubic equation and generally seen as the greatest mathematical treatise of the sixteenth century, has been characterized as the first decisive advance over the attainments of the giants of classical Greek mathematics. The Dictionary of Scientific Biography lists medicine as the first of Cardano's qualifications and declares that among the physicians of Europe, he ranked second only to Vesalius. Yet another Cardano emerges in this new book: the leading astrologer of his day, rivalled only by Luca Gaurico and later by the Elizabethan magus John Dee.

It was no doubt inevitable that historian Anthony Grafton would bring his formidable intellect and lucid style to bear on Cardano. The Princeton professor has already completed a magisterial, two-volume study of the great Renaissance classical scholar Joseph Scaliger, whose father's greatest claim to fame was, in Grafton's words, "the most savage book review in the bitter annals of literary invective", a 900-page rebuttal of Cardano's On Subtlety.

Born in Italy in 1501, Cardano set out on the path to becoming Europe's most famous astrologer with the publication of an accessible astrological handbook in 1538. Five years later he achieved international notoriety when it was reissued as Libelli Duo in an enlarged version with 66 genitures, or birth horoscopes, of notable people. The book was

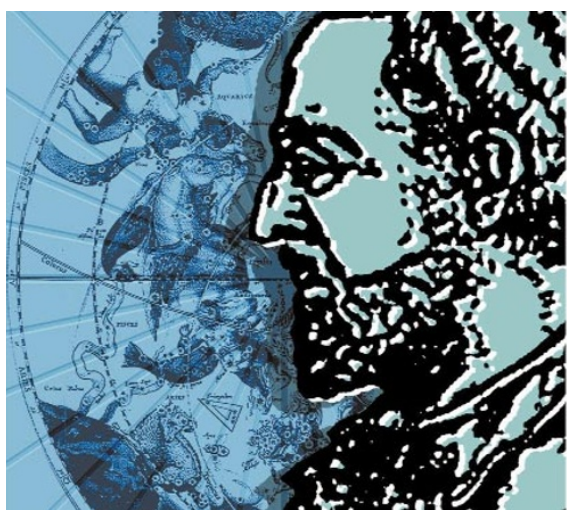

widely circulated, perhaps as much for its gossip and character assessments of the rich and famous as for its astral clues. That was in 1543, the year that the same publisher Johannes Petreius of Nuremberg — brought out Copernicus's De Revolutionibus.

Two years later Petreius printed Cardano's most enduring book, his Ars Magna, an event off Grafton's map, although he does include a great deal of other fascinating information about the Nuremberg publisher. In 1547 Cardano produced a further expanded book of genitures, now Libelli Quinque.

Cardano's astrological publications had a variety of consequences. Now a controversial figure, he also became a sought-after adviser who could both prescribe medicine and deliver prognostications. He lived in a world of contradictions, where the messages from medicines and from the stars were fraught with ambiguity. It is this complex world of Renaissance growing pains that Grafton carefully dissects, with all its mixed signals and complexities. And he does it with literary grace and marvellous turns of phrase: "Cardano promised those who walked the paper corridors of his collection the secrets of both natural and political power". His acquaintance Rheticus, Copernicus's only disciple, was none too pleased at being portrayed - in Grafton's vivid description - "as Dr Watson to Cardano's astrological Mr Holmes". In an "unbuttoned" autobiography Cardano portrayed himself as a "wacky professor", Grafton writes, considering this "a partial mirror of his fractured self".

Elsewhere, Grafton has written engagingly on the history of the footnote; here he reveals himself to be an erudite master of endnotes. A rich array of esoteric sources never hinders the narrative, but provides the evidence at the end of the volume. And when the desired materials aren't available from Cardano, because his letters had been burned, Grafton switches effortlessly to a well-documented case of how to give economic advice to clients by the infamous seer Nostradamus. Only very rarely can one catch Grafton out. During a meeting with John Dee in 1552, when Cardano had come 
to Britain to treat the Archbishop of St Andrews for asthma, Grafton misidentifies "Joannes Franciscus" as Sir John Cheke, whose horoscope Cardano had cast, rather than as Jofrancus Offusius, an astrologer temporarily living off Dee's patronage.

For the overwhelming majority of Nature's readers, astrology has been relegated to the rubbish bin of history. Of what use is all this exotic scholarship? Let Grafton speak: "A knowing and thinking subject, Cardano modified, manipulated, or invented contradictory languages as he needed them. He was not always sure why he used them as he did, or on what assumptions they rested, or even whether the predictions he spoke came to him from his own intellect, the stars, or daemonic inspiration. But he knew and said that he stood at the center of a cosmos that his own mind could only mirror in a fractured, incoherent way. He deserves to be heard." Owen Gingerich is at the Harvard-Smithsonian Center for Astrophysics, Cambridge, Massachusetts 02138, USA.

\section{Not just a pretty Polly}

\section{The Alex Studies: Cognitive and Communicative Abilities of Grey Parrots}

by Irene Maxine Pepperberg

Harvard University Press: 2000. 434 pp.

$\$ 39.95, £ 24.95$

\section{John C. Marshall}

From King Solomon to Walt Disney by way of Saint Francis of Assisi, the desire to converse with other species has run deep in the human psyche. The attraction furthermore appears to split we humans into two camps: those who wish to learn the 'language' of animals and those who are determined to teach them ours. On the whole, the former group has scored more scientific victories than the latter. The decipherment of bee dancing, for example, was a far greater achievement than any number of overexcited translations of chimpanzees waving their arms about in a bad imitation of American sign language. Worse, attempts to teach spoken English to apes was even less successful. The entire line of research in which we attempted to impose our communication system on another species was, it seemed, dead. The undertaking had run down the curtain and joined the choir invisible.

Not so. In The Alex Studies, Irene Pepperberg summarizes the first two decades of a project to communicate with African grey parrots (Psittacus erithacus). Pride of place in this enterprise is given to the Alex of the title. In some ways, this research programme has the look of a rational pursuit: parrots,
Pepperberg points out, have "a complex social system and a long life" and, more crucially, they do seem to 'mimic' human speech moderately well. On the debit side, many studies of mimetic birds have conspicuously failed to establish two-way speech communication with humans in properly controlled laboratory settings.

Pepperberg argues convincingly that the kinds of classical and operant conditioning techniques deployed in those prior investigations of mynahs, magpies and parrots were not well matched with the highly interactive, social manner in which mimetic birds acquire calls and songs in their natural environment. Accordingly, she modified an earlier technique of Dietmar Todt's, in which "humans assume roles played by psittacine peers in the wild". In Todt's original procedure, "one human is exclusively the principal trainer of each parrot, asking questions and providing increased visual and vocal attention for appropriate responses. Another human is exclusively the model for the parrot's behavior and simultaneously the parrot's rival for the attention of the principal trainer." In these circumstances, Todt's parrots learned relatively quickly (within a day) to mimic phrases produced by the 'rival'. But this behaviour is more akin to 'antiphonal duetting' than to functional communication, and would not surprise any parrot owner.

In Pepperberg's extension, one human 'trains' another to name objects, and to describe their colour, or shape, or number. The bird watches and is then brought into the game as the second 'pupil'. The two humans sometimes reverse their roles of trainer and trainee, and the bird is occasionally included in three-way interactions. Thus the birds "do not simply hear stepwise vocal duets, but rather observe a communicative process that involves reciprocity". Furthermore, the bird can "effect environment change" (that is, obtain the object) by vocalizing "Wanna ..." plus some word in its vocabulary. The evidence presented suggests that Alex could acquire vocal labels for objects, actions and attributes to a level similar to that reached in earlier experiments with great apes taught to deploy visual signs or tokens.

Some generalization to novel situations is found, along with a very limited combinatorial ability. There were also indications that Alex can respond appropriately to sameness, difference and absence. Comprehension of relative size was fair, and that of object permanence was good, comparable to that demonstrated in young children by the Swiss developmentalist Jean Piaget.

For my money, the most interesting chapters were those concerned with just how similar (or dissimilar) to human speech is the parrot's imitation, and how the bird actually produces these sounds with a vocal apparatus that is very different from our own. In a sense, these chapters tell us as much about humans as about parrots - however distorted the signal, we are predisposed to hear speech. The final chapter includes fascinating information about the social behaviour of mimetic birds in the wild, and makes one wish for an entire book on this topic.

With respect to captive parrots, readers will have to make up their own minds about whether it was all worth the effort (on either Alex's part or that of Pepperberg). I suspect that those who were unimpressed by the proto-linguistic skills of chimpanzees and dolphins will remain undazzled by those of parrots. But people who thought these earlier attempts at interspecies communication were a major breakthrough in evolutionary science will no doubt be delighted with Alex's achievements and untroubled by how far back one must go to find a common ancestor

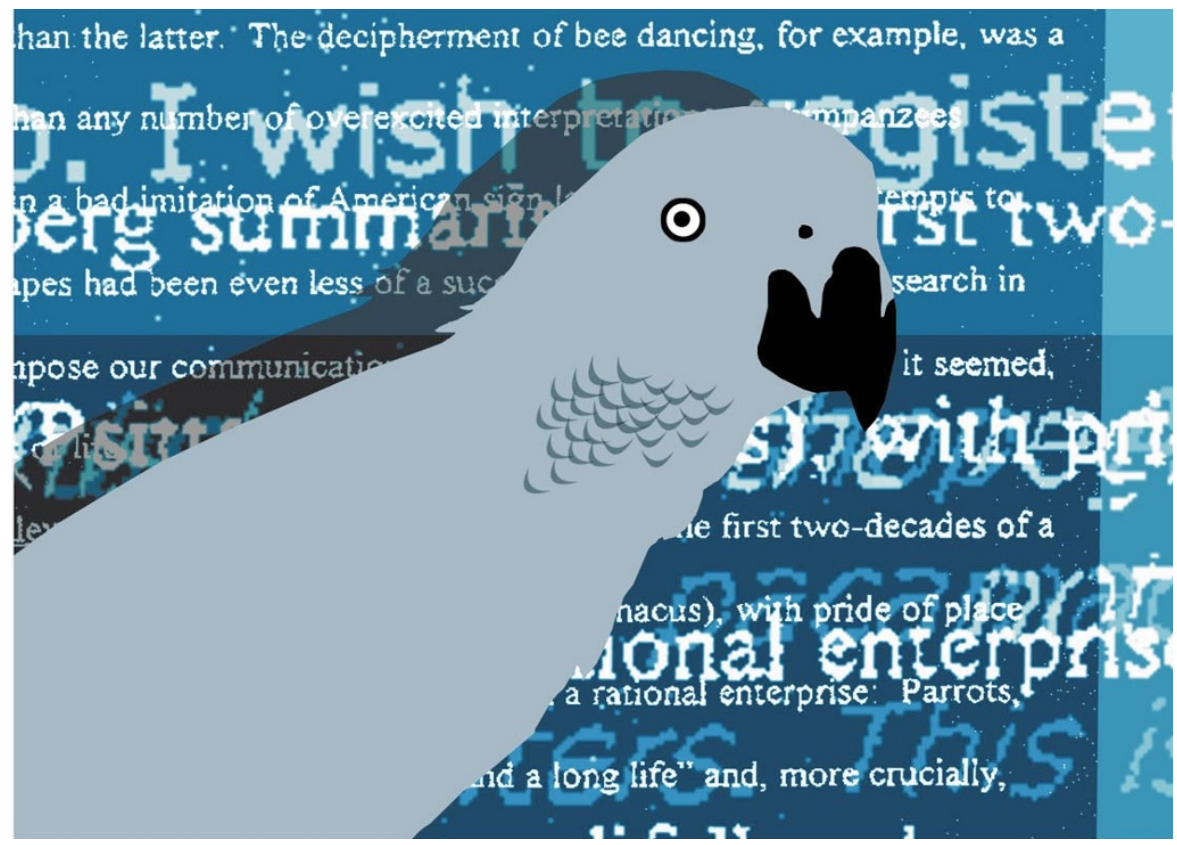

